\title{
Deliberative Bureaucracy: Reconciling democracy's trade-off between inclusion and economy ${ }^{1}$
}

John Boswell, University of Southampton

Jack Corbett, University of Southampton

\begin{abstract}
Deliberative democrats have long considered the trade-off between norms of inclusion and efficiency. The latest attempt at reconciliation is the deliberative systems model, which situates and links individual sites of deliberation in their macro context. Yet critics argue that this move to scale up leaves inclusive practices of citizen deliberation vulnerable. Here, we seek to mitigate these concerns via an unlikely source: bureaucracy. Drawing on the notion of policy feedback, with its attendant focus on how policies (re)make democratic politics, we envision a deliberative bureaucracy where implementation and service delivery are imbued with norms of justification, publicity and, most radically, inclusion. Looking at promising contemporary governance practices, we argue that a deliberative bureaucracy, with the rich public encounters it might foster, can reconcile the desire to scale up deliberative democracy to whole systems with the desire to hold on to the benefits of scaled-down citizen deliberation.
\end{abstract}

Keywords: deliberative systems, deliberative democracy, bureaucracy, public administration, policy feedback

Acknowledgments: Thanks to David Owen, Rikki Dean and the anonymous reviewers for very useful comments on earlier drafts.

\footnotetext{
${ }^{1}$ This paper is forthcoming in slightly adapted form with Political Studies.
} 


\section{Introduction}

The issue of scale is again front and centre in deliberative democracy. Where a decade or so ago deliberative democrats sought to reinvigorate democratic theory and practice by scaling down democratic arenas to enable authentic deliberation among citizens free from the coercive influences of the macro-political context, the general emphasis in this school of thought is now on scaling back up (see Mansbridge and Parkinson 2012). Most proponents of this ideal now embrace a 'systemic' view, seeing deliberation as an activity occurring across a range of interconnected but differentiated democratic arenas that collectively make up a deliberative system. Driven in large part by a desire to reconcile the micro and macro tendencies in deliberative democratic theory and research, deliberative systems is emerging as the new orthodoxy.

Yet, just as some within the broad deliberative democratic church were always wary about the limitations of a scaled down view (see Chambers 2009), so too are others beginning to express scepticism about the systemic view (see Owen and Smith 2015). The worry is that, on closer inspection, a systemic view begins to look vulnerable to elite domination, marginalising the 'free and equal citizens' long at the centre of the classical account of deliberative democracy. Democracy's longstanding tension between norms of inclusion and governing economy is rearing its head again. And so, as the systemic turn gathers momentum, will the participatory potential of deliberative democratic theory be left behind? Must the role of the citizen diminish in the move to conceptualising and striving for deliberative democracy at the large scale?

In this article, we seek to reconcile the seemingly divergent demands of economy and inclusion in the deliberative systems approach. To do so, we look to an unlikely source: bureaucracy. Bureaucracy can be seen as unlikely not so much in the sense that it is antithetical to deliberative democratic ideals - though it has long been associated with precisely the sort of elitism that worries sceptics of the deliberative systems approach — but that it seems beside the point. In stylized accounts of how democratic politics does and should work, deliberation is about will formation, whereas bureaucracy is largely about what occurs after that: deliberation is about input, and bureaucracy about output. However, in this paper we argue deliberative democrats have under-recognised the potential of public deliberation after an official decision is made, as decisions are turned into concrete policies on the ground. We argue that an emphasis on processes of policy feedback, with an attendant focus on how bureaucratic modes of administration and delivery affect interaction between 
citizens and the state, has potential to help resolve the inherent democratic tensions between inclusion and economy. Bureaucracy emerged, after all, as a solution to the problem of governing at large scales. It has far greater reach and engenders more sustained, deeper interaction with ordinary citizens than any mechanism of input into executive or legislative decision-making can realistically hope to achieve.

Yet, of course, if bureaucracy matters for deliberative systems, then the aforementioned concern about elitist technocracy becomes more pressing. Intuitively, the faceless bureaucrat does not appeal as a likely champion of the face-to-face deliberation that sceptics worry will drop away in the move to deliberative systems. What little attention has been paid to this area in the deliberative democracy literature tends to present a more complex picture than this common stereotype, but it is generally no more optimistic (Parkinson 2004; Papadopolous 2012). Here, contemporary trends in public management are seen to depoliticise and decouple bureaucratic processes from decision-making inputs. We argue, however, that existing accounts present these reforms in overly monolithic and static form (see Bevir and Rhodes 2010). For one, they overlook the development of bureaucratic practices which enable greater inclusion in deliberative systems. But, they also overlook the potential for these practices to be further reformed - indeed, in much the same way that deliberative democratic innovations have iteratively changed processes of decision-making input. Building on these more promising precedents, we envision a deliberative bureaucracy.

Though we will develop the idea in much more detail in later sections, we define it here for clarity. Drawing on and adapting norms and ideals expressed in deliberative democratic theory more broadly, we argue that deliberative bureaucracy should be understood as a justificatory, public and inclusive approach to the implementation of public policies and delivery of public services. It is justificatory in the sense that bureaucrats (or the myriad private and third sector actors who now perform coordination, oversight and delivery roles) should seek to explain the actions they take in administering laws and policies, making explicit their interpretation of those laws and policies, the discretion they have drawn on in the process, and their reasons for doing so. It is public in the sense that those exercising such interpretation and discretion should be accountable both to the institutions whose will they are carrying out and to the broader public they serve. And, most importantly and most radically, it is inclusive in that affected citizens should be involved in shaping exercises of interpretation and discretion as far as is practicable. 
Seen in these terms, we argue that a deliberative bureaucracy, with the rich public encounters it might foster, can reconcile the desire to scale up deliberative democracy to whole systems with a recognition of the benefits of deliberation scaled down to the level of citizen interaction. Indeed, it can strengthen both by compensating for the democratic shortcomings of decision-making inputs, but also enhancing a positive feedback loop that can sustain and channel broader deliberative capacity across systems. Striving for and working with a more deliberative bureaucracy, then, is an essential step towards the broader goal of developing more robust deliberative systems.

The argument we outline briefly here is developed fully in the five sections that follow. The first sketches out the developing schism in deliberative democratic thought prompted by the systemic turn. The second introduces the notion of policy feedback to demonstrate in particular how bureaucratic modes of administration and service delivery can have a profound impact on broader deliberative capacity. The third articulates in much greater detail the features of a deliberative bureaucracy and specifically highlights their potential to compensate for perceived weaknesses in the current deliberative systems account. The fourth section looks to the existing public management literature for examples of how deliberative bureaucracy is already happening, and proposes ways in which it could be instantiated more often and more deeply. The concluding section explains how a more deliberative bureaucracy can sustain a virtuous feedback loop that enables greater deliberative capacity in more traditional input terms as well.

\section{Taking stock of the systemic turn: revisiting scale and deliberative democracy}

The aim of this section is to briefly sketch out the challenge of scale in deliberative democracy. This involves a brief account of the critique which informs deliberative systems theory, and a more novel consideration of the criticisms aimed at this emerging orthodoxy. Both steps are important in setting up our key claim: that policy feedback looms as a source of enormous potential. Both work to outline the issues at stake in the turn to deliberative systems, and the divisions that it stirs up again over balancing inclusion and economy.

Central to the renaissance of deliberative democracy as an ideal over recent decades has been the importance of empowering citizens in democratic politics. This vision is one in which everyone has the capacity to develop and express their opinions on matters which pertain to 
them (e.g. Cohen 1989). The problem that has long loomed here, though, is one of practicality. Compared to the parsimony offered by the thinner aggregative version of democracy, deliberative democracy has long faced a dilemma. As John Dryzek (2001, 652) explains: "The key constraint here is one of economy. Robert Dahl and many others have pointed out that meaningful participation in collective decision-making by more than a tiny minority is inconceivable in contemporary nation-states (and, indeed, in most of their component units)". And, crucially for our purposes, this dilemma has been a source of differential interpretation within the deliberative democratic literature: all agree that affected citizens should have voice, either directly or through a representative, but the frequency with which such representation should occur, and the strength of ties between representatives and those they make claims on behalf of, reflect broad divergences. In some theoretical prescriptions, there is greater emphasis on mass involvement in face-to-face deliberation (Dryzek 2000); on other accounts, however, such deliberation has largely been restricted to 'public face' representation, usually via elite actors who speak on behalf of their constituents (Gutmann and Thompson 1996). This same divergence is apparent in related empirical work. For many scholars of deliberative democracy, the emphasis has been on instantiating and assessing mini-publics and other innovations of face-to-face citizen deliberation (see especially Fishkin 1997; 2009); for others, however, the focus has remained squarely on established democratic institutions and practices of 'public face' representation involving elected officials (see especially Steiner et al. 2005).

The critique which has inspired the emerging systems view is that both versions are overly micro in orientation (Pateman 2012). The overarching concern is that an account of a deliberative democracy as a whole, and not just democratic deliberation in isolated pockets, ought to pay much more attention to the ways in which the face-to-face and 'public face' practices and institutions of deliberation connect and interact. On the one hand, this has involved a welcoming back into the fray of rhetoric, and the highly asymmetric political communication it engenders (Chambers 2009). In this sense, it is seen as less important that elite political actors engage in ideal deliberation with each other, and more important that their 'public face' communication contributes to the deliberative system by clarifying and publicly justifying elite stances and prompting broader face-to-face deliberation in civil society and among citizens. On the other hand, the shift away from the micro focus has also involved acknowledging that the (presumably) perfect democratic deliberation in minipublics only matters insofar as it influences the macro-political context in which it occurs 
(Hendriks 2006). This has led many deliberative democrats to stress the importance of connections which link mini-publics and other micro practices to the broader public sphere or empowered institutions of policymaking. Crucially, the systems' approach explicitly works not to replace the micro with the macro, and instead to connect the two. Indeed, one of its foundation stones - the text from which its name is drawn - represents an effort to better preserve the place of ordinary citizens and their 'everyday talk' in broader democratic discussion (Mansbridge 1999).

Yet a critical reading of these manoeuvres reveals that the systemic account actually risks diminishing the role of the affected citizens at the centre of the classical account of deliberative democracy. Owen and Smith (2015), for instance, note that the systemic approach seems to favour the macro over the micro. Central to their critique of Mansbridge et al.'s (2012) "manifesto" is a concern that the systems account fails to sufficiently promote and safeguard the generative capacity of face-to-face deliberation among affected citizens (such that, they point out, a system may not feature any such deliberation at all). The absence of guaranteed citizen influence_-via either endorsement of asymmetric 'public face' representation or substantive policy impact deriving from their face-to-face deliberationsallows for epistemic limitations, including significant technical or administrative barriers to acting on professed opinion. More prosaically, it can also help to manage conflict and enable ongoing commitment to processes of conciliation and engagement. However, critics worry that it also leaves the systemic account vulnerable to elite domination. After all, it is powerful actors who are best placed to stay with an issue and steer any course of action towards their interests, often at the expense of those deriving from face-to-face citizen deliberations (Boswell 2016).

Yet the systemic account remains very attractive in its capacity to bridge the micro focus of deliberative democratic research and practice with its macro theoretical ambitions. So, the key question becomes: is there a way to safeguard the place of citizens, and the significance of their deliberations, in a deliberative systems account that is attentive to the importance of connections to elite and empowered political institutions? Or, more simply, is there a way around this age-old trade-off between inclusion and economy in its new systemic form? 


\section{Beyond a focus on inputs: Policy feedback, bureaucracy and deliberative capacity}

In the section that follows, we answer in the affirmative: through the notion of deliberative bureaucracy, we seek to attend to the problem of including citizens while seeking to scale up. The key to this argument is to note the overarching focus within deliberative democracy, whether the face-to-face, 'public face' or the hybrid systems' version, has been concentrated on input to will formation. The point of the previous section was to show that though the tensions between the face-to-face and 'public face' accounts have always existed, the move to a systems perspective has, in trying to resolve them, actually thrown them back into sharper relief. The point of this section is to suggest that any resolution will require a more thoroughgoing systems account which looks well beyond the mere inputs to policy decisionmaking. We take up this mantle, drawing on the notion of 'policy feedback' well established in the empirical scholarship of public policy and administration (eg. Mettler and Soss 2004; Patashnik and Zelizer 2013). Our emphasis is on extending the focus of deliberative democrats beyond inputs to incorporate a nuanced understanding of how policies make democratic politics.

Policy feedback refers to the dynamic ways through which policies impacts on the political thought and activity of citizens (see Mettler and Soss 2004). Of particular interest to us in this paper is not so much the content of policies - although obviously these can have important implications for membership of a system, as interpretive scholars like Hajer (2003) have observed - but their delivery, which remains comparatively neglected in accounts of deliberative governance. There has been a particular focus in policy feedback scholarship on the welfare state and the engagement between the state and welfare recipients (see Mettler 2002; Soss and Schram 2007; Dubois 2010). Richly detailed empirical work has shown how certain modes of service coordination and delivery can be empowering, encouraging and resourcing recipients of policies and services to assume fuller rights and roles of democratic citizenship, while other modes can have the opposite effect, rendering citizens voiceless, cowed or frustrated (see Schram and Silverman 2013).

Seen in these terms, deliberative democrats have largely ignored the prospect of policy feedback. Theoretically, deliberation even in the systemic sense has been conceptualised as constructive of policies and not vice versa, focused on the process of opinion and then will formation. Equally, the empirical focus in studies of deliberative democracy has centred on the institutional architecture and its specific design features that give shape to decisions. These studies are deeply attentive to the ways in which citizen demands are mobilised and 
filtered through to empowered venues of decision-making (eg. Stevenson and Dryzek 2014), but they seldom if ever sustain their focus on the 'long march' of laws and policies through the administrative institutions and into their implementation at the street level, let alone through to their eventual reception and the wider effects. And, in practice, the emphasis has been on perfecting institutional design, with a view to ensuring that normatively better demands are made of elites and institutions (see Fung 2015). The emphasis is still very much on inputs to political decision-making, not on the policies that follow on.

The essential point is that policies, and citizens' experience of them, have major ramifications for deliberative capacity at the broad scale. Policy feedback matters precisely because it entails mass publics. Focusing on how policy decisions are transformed into action on the ground offers the potential for deliberative democrats to begin to reconcile the apparently divergent demands of inclusion and economies of scale. And the best place to begin in searching to tap that potential lies in the lasting solution to the problem of governing at large scale: bureaucracy.

Before we begin the work of laying out what a deliberative bureaucracy might look like, however, we want to lay out two very clear caveats.

One is that while we acknowledge the notion of policy feedback is indelibly linked to David Easton's seminal and controversial work on the political system, we do not mean to invoke the associations that come with this move (notably, a problem for the systemic turn in deliberative theory more broadly, too). In Mettler and Soss's (2004) authoritative account of policy feedback, they seek to distance themselves from Easton-claiming that his account of feedback is underdeveloped - and assert a longer and more diverse scholarly lineage for the concept. Others, like Henrik Bang (1998) whose work we draw on later, are much more sympathetic to Easton and dispute his association with a conservative functionalism. We do not want to be drawn into this debate, but simply highlight it to show that engagement with the concept of 'policy feedback' need not entail an unquestioning appeal to Easton's systems theory and its broader connotations.

Two is that we acknowledge that the distinction between inputs and bureaucracy remains stylized. The reality of contemporary governance is messier and more contingent. Modern bureaucracies, and the horizontal networks that they engage with, are not simply charged with turning inputs into outputs. They are frequently engaged in agenda-setting work as well. Indeed, the best known example of democratic innovation in action-Participatory 
Budgeting - is typically commissioned and run by municipal bureaucracies (see Pateman 2012). More broadly, much work on deliberative governance already acknowledges and grapples with the dynamics of networked forms of deliberation on policy inputs (eg. Papadopoulos 2012; [omitted]). Yet, as we further elaborate on below, policy feedback is still typically neglected in this scholarship. There is significant untapped potential in following through the messy technical and professional processes of administration and implementation to understand the effects of service configuration and delivery.

\section{What a deliberative bureaucracy might entail}

The classical Weberian bureaucracy is underpinned by a form of technocratic rationality that appears incommensurable with deliberative democratic ideals: bureaucracy, in this sense, appears faceless, not face-to-face; hived away, not open to public scrutiny; and hierarchical and elitist, not inclusive of citizens. Yet, as we allude to above, this describes a stylised caricature of bureaucracy that is well wide of the contemporary orthodoxy in the public administration literature. Bureaucracy in modern liberal democracies retains some of these classical hallmarks, but the trend in the last few decades has been towards hollowing out, opening up and branching across horizontal, networked relationships with civil society, private interests and citizens, as public bodies strive to build and maintain their legitimacy, often in a context of dwindling resources and intensifying problems (O'Toole 2015). Indeed, though we use the term 'bureaucracy' in this paper for rhetorical effect - and because, unlike terms such as 'governance', it retains a tight association with politics beyond will formation - in fact it seldom appears in the public administration literature anymore, replaced instead by a multiplicity of overlapping terms and concepts that attempt to capture the more limited, open, relational nature of modern policy implementation and service delivery. The tendency among the minority of deliberative democrats who have acknowledged these changes in governance is to see them as problematic (see Parkinson 2004; Bevir 2006; Papadopolous 2012). However, we argue that there is significant deliberative potential in bureaucracy understood in these terms. By applying the important lessons, tools and ideas of the deliberative turn as applied to democratic input we can enhance and widen the spaces of deliberation that are already available in policy implementation and service delivery. A deliberative bureaucracy, in this sense, can better reconcile the demands of economy and inclusion in large scale deliberation. 
As such, identifying three such features as being especially important for the particular nature of bureaucracy, we hold that greater attention should be paid to ensuring that policy implementation and service delivery in deliberative systems be as justificatory, public and inclusive as possible. We dwell on each of these criteria below. Our particular emphasis is on the last of these criteria, as it is here we find the most radical potential for restoring a robust connection to citizens in the systems account of deliberative democracy.

\section{Justificatory bureaucracy}

The value of justification in deliberative democracy is most central to, and best associated with, Gutmann and Thompson's (1996) influential account, especially their core principle of 'reciprocity'. For Gutmann and Thompson, actors engaged in debate have a duty to justify their claims in terms that all others can accept. What they have in mind is a form of justification that occurs up to and then at the point of will formation, as political elites outline their positions and ultimately explain the decisions that they have taken to their constituents. What we have in mind is simply extending justification through the process and among a greater variety of actors engaged in the administration and delivery of policies and services. Decisions made at the point of will formation are often provisional, ambiguous and openended - a point not only laboured across the policy and administration literature but one which Gutmann and Thompson (1996, p. 7) acknowledge themselves. For a host of very good reasons - because it secures buy-in from stakeholders, because it recognises bounded rationality around complex or difficult issues, because it allows for adaptability to context and discretion at the 'street-level'-decision-makers want to retain 'wriggle room' for the application of laws and policies. Inevitably, bureaucrats and the non-governmental actors involved in policy oversight and service delivery have to exercise considerable discretion in their interpretation of policies as enacted.

It is important to note here that one of the primary limitations of wide-scale deliberation is seen as epistemic. The concern that greater inclusion can come at the expense of reasoned argumentation about feasible options in the context of complex and technical issues (see Marti 2006). Much of deliberative theory has implicitly_and at times explicitly (see Christiano 2012) — clung to a means-ends distinction, whereby political deliberation focuses on the ends (policy) and bureaucratic processes focus on the most efficient and effective means of achieving those ends. But if we acknowledge that this distinction is false, and that 
the means are a critical political process which entails ramifications for broader deliberative capacity, then there is a need for greater elaboration on the possibilities and obstacles in administration and implementation. Enabling and ensuring the justification of these acts of expert and professional discretion publicly (as we elaborate on below) can better fulfil the epistemic function of a deliberative system while retaining the emphasis on the large scale.

\section{Public bureaucracy}

Though publicity is also a feature of Gutmann and Thompson's account (among many others), it is a deliberative democratic norm best associated with Jon Elster's (1997) 'civilising force of hypocrisy'. Elster's turn of phrase nicely encapsulates the deliberative democratic desire to subject actors' claims to public scrutiny, both so that they can be held to account for any breach of trust and, more fundamentally still, they might be conditioned to couch their justifications in the broader public interest. Once more, the emphasis remains limited to input - the hope is that the process of deliberation prior to reaching a decision be oriented to the public as far as practicable. Once more, then, our claim here is simply that this norm be extended through the policy process. Processes of administration and implementation are by tradition opaque if not entirely behind-closed-doors, dominated by technocrats, experts and the most powerful of stakeholders away from public view. Just as Chambers (2004) argues in relation to input, of course, there may be good reasons to safeguard privacy in some interactions. But a more deliberative political system ought to make delivery open to the public as far as is practicable, so as to mitigate the prospect (not to mention perception) of elite domination of the process. Such a prescription goes somewhat further than the justificatory norm, though is hardly a radical prospect. Neither is it without precedent in contemporary democratic governance - as we will elaborate later.

\section{Inclusive bureaucracy}

Before doing so, however, we hope to dwell in greater detail on the characteristic of a deliberative bureaucracy with the most radical potential - that is, a much more inclusive approach to policy delivery. As our earlier discussion of face-to-face deliberation made clear, inclusion has long been a cherished norm of deliberative democracy. Among leading deliberative democratic thinkers, nowhere is it more central than in the work of -ironically if we consider the risks associated with the turn to deliberative systems outlined in the previous 
sections - Jane Mansbridge. For Mansbridge (1999, p. 25), deliberative democracy is at heart 'a democratic theory that puts the citizen at the center'. Indeed, it is a vision of a more radically inclusive deliberative democracy that underpins her call for greater integration of 'everyday talk' into the broader system, forming the important background to, and holding interconnections with, formal institutions populated by elites. The move to greater inclusion has been the most radical aspect of the explosion of interest in making inputs to the political system more deliberative and democratic, spouting a range of democratic innovations that seek to more centrally involve randomly-selected and self-selecting everyday citizens in the input-focused process of setting, filtering or weighing up demands (see Smith 2009). Yet, as we have argued, it is also this aspect that is most vulnerable in the move to scale up deliberative democracy to whole systems and societies.

As such, we hope to help safeguard inclusion by grafting it equally into the way policies are administered and implemented. There are two ways in which this might be instantiated.

One entails diversifying membership of the public bodies that oversee the implementation of policies and services, in particular by fashioning a larger role therein for lay citizens. Just as a range of democratic innovations have brought citizens and service users closer in to deliberations about input, so too could experimentation be aimed at ways of bringing them into implementation and delivery, either as additional members of existing committees or on designated civil society or citizen oversight bodies. Such manoeuvres would go a step beyond ensuring justification and publicity actively inviting popular scrutiny over affairs that may otherwise fail to garner much attention. There are clear affinities here with the "citizen committees' that Mark Bevir (2006) hopes can challenge technocratic domination in public administration.

More radically, enhancing inclusiveness in political systems might also rest on shifting the relationship between citizens and the policies and services that affect them. Koen Bartels (2013) revisits the notion of 'encounters' between the public and government, in which he notes that the vast bulk of citizen interaction with the political system comes as service users or clients. This remains the motivating logic of bureaucracy; it provides the machinery to effectively deliver services to and extract resources from mass populations.

The long-held perception is that these 'encounters' are apolitical. This is a misconception rooted in an out-dated conception of bureaucracy. The rich encounters between bureaucratic elites and citizens represent a site of immense (albeit often unrealised) potential for 
deliberative systems. Here we draw on the work of Henrik Bang (2011) especially, and in particular his theorising of a shift in the modes of democratic governance away from 'politics-policy' (inputs) to 'policy-politics' (outputs). This move, he argues, is an affect of 'late modernity', where identities are increasingly fluid and political participation is no longer dominated by parties and hierarchies, and its participants no longer motivated or governed by notions of the civic. In Bang's account, which draws heavily on Easton's systems theory, the input side is itself being depoliticised: neoliberalism has led to widespread alienation from representative politics, and a hollowed out state. But Bang goes beyond typical accounts of depoliticisation in that he sees these trends less as indicative of net depoliticisation itself, and more as a displacement of political activity from input to output. He claims that it is in implementing policies, and delivering them on the ground, that bureaucratic elites must engage with mobilised publics. This has given rise to what he terms the everyday makerindividuals who engage in politics on their own terms and for their own benefit, rather than as the dutiful citizens of democratic folklore. Though Bang himself remains wary of deliberative democracy and does not seek to apply its associated terms, it is clear that the rise of everyday makers and their activism entails an important source of 'face-to-face' deliberation on a large scale. Indeed, his account in many ways mirrors Mansbridge's original account of mobilised publics and their 'everyday talk'.

Though Bang's account represents an exciting alternative to the stale orthodoxy of participatory decline, there remains much to dispute about his claims. We acknowledge that his version of participation accords better with policy areas that entail the delivery of services - eg. health, education, welfare — and does not travel so well to arenas such as foreign or macro-economic policy where citizens do not directly encounter the state. We concur with other critics that his argument is optimistically skewed by his empirical work on local governance in Copenhagen, and that the positive trends he identifies may not be occurring to the same extent, or at the same pace, everywhere (see Marsh 2011). But we do not have to accept Bang's claims in full to extract a key insight that does resonate widely: that policies foster interaction among bureaucratic elites and publics, and that these interactions have become ever-more crucial spaces of political action. Indeed, recent research in policy and administration-including some that explicitly draws on the notion of "policy feedback' - is testament to the increasingly important influence of 'street level service users' on the practices and norms of bureaucratic elites (Soss 2000; Dubois 2010). What matters, 
then, is that deliberative democrats focus much more attention on the questions that this crucial insight opens up.

\section{Making policies more deliberative and democratic}

As outlined above, Bang's account gives us hope that these interactions may be characterised by more extensive bureaucratic justification and greater public scrutiny over discretion, and that they can work to foster consequential face-to-face deliberation among citizens and with elites. This final prospect reimagines the sort of radically inclusive system that proponents of the face-to-face account have long cherished. But hope is far from reassurance. Much of the public administration literature paints a much gloomier vision of contemporary bureaucracy. So, the question that remains is how policy feedback can foster generative, mobilising encounters, rather than the sort characterised by elite deception, manipulation, or coercion. We turn now to think about how the transformation of political decisions into policies and services might be made more justificatory, public and, above all, inclusive. To help ground our abstract claims, we make use of contemporary examples from the healthcare sector. Health governance represents a clear and intensively studied area in which, amid the complexities and limitations of modern bureaucracy, modest efforts towards 'democratizing health' along the three key dimensions we identify have occurred. We draw especially on Ellen Stewart's (2016) recent study of the multiple and overlapping participation practices in the Scottish health system - a particularly useful exemplar in our case because it provides a 'citizens'-eye view' that perceptively links micro-practices with system-level concerns.

\section{Justification}

The classical model of bureaucracy sees little need for justification, in that bureaucrats simply exercise the will reached by decision-makers in response to inputs. But this is a long way from the contemporary understanding of bureaucracies and how they operate. Indeed, the defining theme in public administration over the last three decades has been a shift away from bureaucratic government to networked governance. The overwhelming orthodoxy now is that the state has become interpenetrated and interdependent with private sector and civil society actors. There has been an operational shift from hierarchical command and control to horizontal persuasion of, and negotiation with, these partners (O’Toole2015). 
This is not to claim, however, that reciprocity in the sense that Gutmann and Thompson promote has become the norm in networked forms of governance. Crucially, to meet deliberative norms, justification ought to be oriented to the broader interests of the public. Much of the more critical literature on networked governance highlights a tendency towards self-regarding justification: a division of spoils amongst powerful friends (O'Toole and Meier 2004; Papadopoulos 2012). This is the so-called 'dark side' of networks. Such concerns about contemporary practice, though, are not beyond amelioration. Evidence suggests that a key variable is the make-up of the network. More diverse networks, in which pluralities of actors participate on a reasonably equal footing, increase the prospect that justification of discretion exercised by bureaucratic elites be couched in terms of the broader public interest (see Ansell and Gash 2008).

Nowhere is this better exemplified than in health governance. Healthcare is an arena which has long been characterised by networked interdependence. But traditionally these networks have been exclusive and exclusionary, featuring a limited range of powerful groups (government, clinicians, and medical/pharmaceutical interests). In more recent times, there have been moves towards opening them up via the inclusion of other healthcare professionals and, more notably, patient and carer representatives (Baggott and Forster 2008; Lofgren et al. 2011). The levers with which to do this have included both formal institutional innovations, most commonly the co-option of lay people onto healthcare delivery and oversight committees, and informal partnerships, where representatives of patient groups are given access to, and establish working relationships with, senior bureaucrats, professionals and industry representatives.

Stewart's (2016) account of committee work in the Scottish health system provides a cleareyed assessment of the strengths and limitations of this form of public participation. Though she notes the risk of healthcare consumer advocates being co-opted into the system - and thus her stance that such formally 'invited' participation (in which she also includes forms of consultation and democratic innovation) can pose dangers in the absence of reflexivity-she also highlights how the engagement of lay members affects the dynamic of committee work, and forces elite network actors to craft justifications in the broader patient and public interest rather than in narrow professional terms.

To be sure, such justifications can also scarcely be taken at face value as reflecting the genuine reasons of these actors. Often we can infer that the stated reasons of powerful groups 
may masquerade as justification for narrower self-interests. What matters is that they justify their discretion in ways that appeal to the range of actors involved. This is Elster's (1998) 'civilizing force of hypocrisy'. Doing so can mitigate the prospect of powerful actors steering implementation towards their own interests and away from the public goods reached through the deliberative processes of will formation. Seeking ways to effectively diversify networks of policy implementation and delivery-be that through formal institutional innovations or more informal partnerships with a wider variety of civil society actors — ought to represent a key focus for proponents of deliberative systems (see Boswell 2016).

\section{Publicity}

Unlike justification, publicity has long played an important role in the classical model of bureaucracy in the form of procedural transparency. Bureaucrats themselves, in this account, are suitably 'faceless', out of the public glare, but the rules dictating their actions are entirely open to public scrutiny. This image, if it ever existed to any degree beyond stylised form, has subsequently crumbled. Evidence from the public administration literature suggests that decisions are often vague such that bureaucratic elites cannot possibly apply them 'by-thebook'. In fact, they are often left intentionally so in the hope that elites will exercise their expert discretion in implementing policies and delivering services (Kane and Patapan 2006; Durose 2011). The literature also tells us that the machinery of governance is immensely complex, involving increasingly convoluted institutional structures in the public sector (rather than rigidly hierarchical ones) and, of course, a range of interdependent relationships with private and third sector actors. Far from being transparent and immediately apprehensible, policy processes are inherently difficult to discern. Once more, much of the literature in public administration and public policy devoted to the issue is critical of the closed-off, opaque nature of policy implementation and service delivery (see Papadopoulos 2012).

Yet, again, such opacity need not necessarily be the case. There is swelling rhetoric around the notion of transparency, with related impetus to publicise the discretion that bureaucratic and professional elites exercise. There are many ways in which such a commitment might manifest, but to clarify what it might entail it is useful to canvas perhaps the most celebrated bureaucratic innovations in the cause of transparency: the British Food Standards Agency (see Hajer 2009). Established in the wake of the damaging 'mad cow's disease' scandal in the 1990s, the FSA was mandated to be 'open' in its function in order to shore up political trust 
and consumer confidence. This involved pioneering practices of transparency such as 'open data' on industry food safety performance and 'open board meetings' webcast live.

Returning to our healthcare example, we can see similar general shifts. Healthcare providers now routinely publish open data on service outputs and patient outcomes; in addition to wideranging committee work, patient groups and activists have also played a role in bringing about (and ensuring their representation at) a proliferation of oversight bodies that hold health authorities to account at different levels of government or on particular issues of interest; and they have followed the example of the FSA in not just in publicising the proceedings and outcomes of these settings, but in making them occur 'in public' via webcast (see Lofgren et al. 2011 for discussions of each).

This is not to suggest that such innovations exhaust the repertoire for what we might understand by a more public bureaucracy, nor that they are universally successful in practice. Stewart's (2016) 'citizen's-eye view' of the Scottish health system, for example, shows that the proliferation of outreach programmes and processes can compound the baffling complexity of contemporary governance arrangements, with the attendant risk of a disconnecting and depoliticising effect. Yet this patchy track record in innovation does not detract from the fact this represents an important area for deliberative democratic scholars and reformists. Greater conceptual and empirical attention can elucidate the factors which inhibit and enable authentic (and, from the citizens' perspective, comprehensible) publicity in policy implementation and service delivery from a deliberative system.

\section{Inclusion}

Active inclusion of citizens is completely absent from the traditional image of bureaucracy. The public, if envisaged at all, are seen as passive recipients of services and obedient providers of resources. But again, contemporary accounts of public administration and public policy present a much more nuanced picture. In fact, there is an increasing emphasis on the role of citizens at the centre of public policy, both from scholars who see this as normatively desirable and scholars who see it as problematic. The former sees the advancement of 'citizen-centred governance' as a normative commitment that resonates with a broader 'public value' account of public administration (see Moore 1995). These scholars point to dwindling bureaucratic competence. They argue that the cast of bureaucratic elites engaged in contemporary networked governance are ill-equipped to tackle complex issues such as 
climate change, the ageing population and unemployment on their own. They celebrate the cause of bureaucratic co-production with citizens, and point to emerging examples in practice (Alford 2009). However, many public policy and administration scholars remain sceptical about the nature of these changes. For many, the rhetorical shift to 'citizen-centred governance' policymaking is a fig-leaf for the 'responsibilization' of complex and multifaceted policy problems (see Rose 2000). These scholars bemoan the retreat of the state and the 'depoliticization' of a multitude of governance issues. Studies portray citizens and voluntary organizations as having been left to deal with mounting problems themselves in the absence of sufficient state support (e.g. Ilcan and Basok 2004; Clarke 2005). We will return to concerns about depoliticization in the following section when we discuss feedback loops in the deliberative system. For now, however, the point is that this development nevertheless opens up the prospect (albeit often unrealised) of active inclusion in policy implementation and service delivery.

Again, it is useful to turn to health governance for an example. In this sector, we see growing calls for 'patient-centred care' which echo the claims for citizen-centred governance. Though 'patient-centred care' has many committed proponents, it, too, attracts cynics and critics (e.g. Teghtsoonian 2009). 'Patient-centred care' is, to these sceptics, a euphemism for the 'choice' / 'responsibilization' agendas that enable the retreat of the state. Yet, regardless of the motivations behind the calls for 'patient-centred care', an important broader effect has been an iterative, incremental shift in the mode of encounter between health's frontline staff and the citizens they serve. Rather than treating citizens as passive recipients in classic doctorknows-best mode, the emerging practice - accelerated by calls for 'patient-centred care' - is for greater discussion between health professionals and individual patients and their carers about their specific care needs (Dent 2006). Of course, this 'deliberation at the frontline' typically remains far from the ideal, and far even from the sort of limited deliberative and/or democratic contribution we might expect in systemic terms. It remains vulnerable to serious asymmetries of knowledge and power. But it undoubtedly represents a political site of considerable importance in deliberative systems' terms.

The most radical aspect of Stewart's 'citizen's-eyed' account is her analysis of the political nature of these service encounters (see also Stewart 2015). She focuses especially on what she calls 'subversive service use' among young people - a group typically missing from accounts of active engagement in committee work, consultation events or protest in the health sector, and more broadly dismissed as politically apathetic. She shows how her avowedly 
non-political interview participants were in fact engaged in 'everyday creativity' to reshape their service encounters. For example, she describes young people as engaging in an active process of 'negotiating diagnosis', drawing on their stores of local or everyday knowledge to challenge paternalistic medical advice and assert great agency over their service use.

While Stewart is careful to recognise the dangers of romanticising such resistance, her citizen's-eye account at least recognises 'street-level service use' as a crucial site of political interaction. An appreciation of policy feedback alerts us to the need for modes of service delivery that enable these subtle forms of agency, especially among those resistant to 'invited' forms of inclusion. The question becomes one of how to build on the potential for making these interactions complementary elements of a deliberative system.

\section{Enhancing the feedback loop in deliberative systems}

Moving towards a more deliberative bureaucracy matters not just because it can make up for growing deficits in input: it matters because bureaucracy and politics are intimately intertwined. The message from the policy feedback literature is clear (e.g Soss and Schram 2007; Patashnik and Zelizer 2013): the content of opinion and will formation, and the capacity of individuals to engage in democratic processes therein, is profoundly shaped by how existing policies are implemented and citizens' experiences of these encounters. A virtuous feedback loop can help to safeguard rather than sacrifice the place of ordinary citizens in the deliberative system. Our account has two key implications for this goal.

First, we suggest that striving for a more deliberative bureaucracy_-rather than continuing to focus solely on reforming inputs to the decision-making process-will help to enhance this feedback loop. This is especially important in the context of mounting discussion about 'deliberative capacity' (see especially Dryzek 2009). Much emphasis is placed on its importance to deliberative systems, but with little corresponding guidance on how to actually go about growing such capacity. Shifting the focus beyond input represents one approach with immense potential. Evidence from the policy feedback literature suggests that the more that affected citizens are aware of and engaged in the oversight of implementation, the more active they are likely to be in asserting their citizenship rights and articulating their policy demands (see e.g. Soss 2000). By seeking to explore and seed deliberative capacity in implementation and service delivery, then, deliberative democrats will also indirectly enhance deliberative capacity in the inputs to democratic decisions. 
Health governance again represents a promising example. The rise of healthcare activism, intensified by institutional incorporation in oversight and public scrutiny, is increasingly bubbling over from policy implementation and service delivery to a broader political focus: healthcare activists want to have a say not just over how policies are implemented and how services are delivered, but over what those policies and services are (Curry et al. 2011). Their demands increasingly centre around ameliorating or undermining policies of service rationing, privatisation and contracting out. In other words, they are beginning to challenge the depoliticization of healthcare.

Second, we suggest that an appreciation of the dynamics of policy feedback can help to direct further efforts to build broader deliberative capacity. In particular, there is considerable potential in channelling some of the subtle and subversive forms of 'street-level service use' among hard-to-reach publics into more active and traditional forms of engagement. There may be mileage in encouraging and enabling those who suffer adverse service experiences to become involved in formal participation and oversight work (eg. committees). But, as Stewart (2015) favours, it may be that street-level experience can also be channelled into more adversarial forms of protest to constitute a more visible and vocal 'challenge' in broader systemic terms.

Again, if we look to the health sector as an example, the emergence of patient groups clustered around specific diseases or causes appeal as promising counterweights to the power and knowledge asymmetry that inevitably afflicts 'deliberation at the frontline'. Evidence suggests that these groups can act as brokers for individual patients in their interactions with medical professionals, and as sources of solidarity and learning for patients and carers facing the same diagnosis (see Lofgren et al. 2011). As such, there would seem to be a particularly important role for third sector groups and activists in providing and shoring up the channels that can connect frontline service encounters with other components of the broader deliberative system.

\section{Conclusion}

Our key claim is that the long-standing tension between inclusion and economy in deliberative democracy — one rearing its head again in the systemic turn in deliberative theory - can best be remedied through reference to policy feedback and thus recourse to a more deliberative bureaucracy. Deliberative democrats should be seeking to enhance 
justification, publicity and especially inclusion in deliberative systems beyond mere inputs to political decisions. We have been careful to caution that there are many obstacles to the realisation of this potential, and that contemporary trends as identified in recent public administration and public policy literature do not necessarily engender hope. Nevertheless, policy feedback represents a hitherto untapped area focus for theorists, empirical researchers, and practical reformers interested. By shifting the focus, and striving for a more deliberative bureaucracy, there is potential to deliver the radically inclusive form of democracy that has long motivated deliberative democrats, and that looms as especially vulnerable in the systemic turn in deliberative democratic theory. What is especially important about this imperative is that a more deliberative bureaucracy can contribute to a positive 'feedback loop'. Doing so can seed greater deliberative capacity among affected citizens to identify, articulate and follow through on new demands. Most importantly, it looms as the only practical way of doing so at the sort of scale that deliberative democrats crave.

The prospect of a more deliberative bureaucracy gives rise to a genuinely systematic account of deliberative democracy: one which reimagines rather than sacrifices the active role of citizens in democratic life. The task that remains for deliberative democrats more broadly is to extend the lessons from the booming literature on democratic innovation in input to think about, and empirically assess, how encounters between citizens and bureaucratic elites across the spectrum of governance issues can enhance active, robust, and consequential inclusion at the large scale. 


\section{References}

Alford, John, Engaging Public Sector Clients: From Service-Delivery to Co-production, (Basingstoke, Palgrave Macmillan, 2009).

Ansell, Chris and Gash, Alison, 'Collaborative governance in theory and practice.' Journal of Public Administration Research and Theory 18 (2008), 543-71.

Baggott, Robert and Forster, Rudolf 'Health consumer and patients' organizations in Europe: towards a comparative analysis.' Health Expectations, 11 (2008), 85-94.

Bang, Henrik P. 'David Easton's postmodern images', Political Theory, 26 (1998), 281-316.

Bartels, Koen P.R. 'Public Encounters: The History and Future of Face-to-Face Contact between Public Professionals and Citizens.' Public Administration, 91(2013), 469-483.

Bevir, Mark, 'Democratic governance: systems and radical perspectives', Public Administration Review, 66 (2006), 426-436.

Bevir, Mark and Rhodes, R. A W., The State as Cultural Practice, (Oxford University Press, Oxford, 2010).

Boswell, John, 'Deliberating downstream: Countering democratic distortions in the policy process', Perspectives on Politics (2016).

Chambers, Simone, 'Rhetoric and the Public Sphere: Has deliberative democracy abandoned mass democracy?', Political Theory, 37 (2009), 323-350.

Clarke, John, 'New Labour's citizens: Activated, empowered, responsibilized, Abandoned?', Critical Social Policy, 25(2005), 447-463.

Cohen, Joshua, 'Deliberation and democratic legitimacy', in Alan Hamlin and Phillip Petit (eds.), The good polity: normative analysis of the state, (New York, Blackwell, 1989), 17-34. Christiano, Thomas. "Rational deliberation among experts and citizens." Deliberative systems: Deliberative democracy at the large scale (2012): 27-51.Dent, Mike. 'Patient choice and medicine in health care: Responsibilities, governance and proto-professionalization', Public Management Review, 8 (2006), 449-462. 
Dryzek, John S. 'Legitimacy and economy in deliberative democracy', Political Theory, 29 (2001), 651-69.

Dryzek, John S, Deliberative democracy and beyond: liberals, critics, contestations (Oxford: Oxford University Press, 2000).

Dryzek, John S, 'Democratization as deliberative capacity building', Comparative Political Studies 42 (2009), 1379-1402.

Dubois, Vincent, The Bureaucrat and the Poor: Encounters in French Welfare Offices. (Farnham: Ashgate, 2010).

Elster, J. 'The Market and the Forum: Three Varieties of Political Theory', in R. Goodin and P. Pettit (eds) Contemporary Political Philosophy: an Anthology. (Oxford, Blackwell, 1997), $128-42$.

Fishkin, James. The Voice of the People: Public Opinion and Democracy (New Haven and London: Yale University Press, 1997).

Fishkin, James When the People Speak: Deliberative Democracy and Public Consultation (Oxford: Oxford University Press, 2009)

Fung, Archon. 'Putting the Public Back into Governance: The Challenges of Citizen Participation and Its Future.' Public Administration Review, 75 (2015), 513-522.

Gutmann, Amy and Thompson, Dennis, Democracy and disagreement, Cambrdige, MA, The Belknap Press, 1996).

Hajer, Maarten. "Policy without polity? Policy analysis and the institutional void." Policy sciences 36.2 (2003): 175-195.Hajer, Maarten A, Authoritative governance: policymaking in the age of mediatization (Oxford, Oxford University Press, 2009).

Hendriks, Carolyn M, 'Integrated deliberation: reconciling civil society's dual role in deliberative democracy', Political Studies, 54 (2006), 486-508.

Ilcan, Suzan, and Basok, Tanya. "Community Government: Voluntary Agencies, Social Justice, and the Responsibilization of Citizens.” Citizenship Studies 8 (2004): 129-144.

Kane, John, and Patapan, Haig, 'In search of prudence: The hidden problem of managerial reform." Public Administration Review, 66 (2006), 711-724. 
Lofgren, Hans, de Leeuw, Evelyn JJ, and Leahy, Michael (eds.) 2011, Democratizing health: consumer groups in the policy process, Edward Elgar, Cheltenham.

Mansbridge, Jane 'Everyday talk in the deliberative system' in Stephen Macedo ed.

Deliberative politics: essays on democracy and disagreement (New York: Oxford University Press, 1999)

Mansbridge, Jane, Bohman, James, Chambers, Simone, Christiano, Thomas, Fung, Archon, Parkinson, John R, Thompson, Dennis F and Warren, Mark E, 'A systemic approach to deliberative democracy', in John Parkinson and Jane Mansbridge eds., Deliberative systems: deliberative democracy at the large scale (Cambridge, UK, Cambridge University Press, 2012), 1-42.

Marsh, David, 'Late Modernity and the changing nature of politics: Two cheers for Henrik Bang', Critical Policy Studies, 5 (2011), 74-89.

Martí, Jose Luis (2006). The epistemic conception of deliberative democracy defended. In S. Besson \& J. L. Martí (Eds.), Democracy and its discontents: National and post-national challenges (pp. 27-56). Burlington, VT: Ashgate.Mettler, Suzanne. "Bringing the state back in to civic engagement: Policy feedback effects of the GI Bill for World War II veterans." American Political Science Review 96.2 (2002): 351-365.Moore, Mark, Creating Public Value - Strategic Management in Government. (Cambridge: Harvard University Press, 1995).

Owen, David and Smith, Graham 'Survey Article: Deliberation, Democracy, and the Systemic Turn', Journal of Political Philosophy, 23 (2015), 212-234.

O’Toole, L. 2015, 'Networks and networking: The public administrative agendas', Public Administration Review, 75 (3), 361-371.

O’Toole, L. and Meier, K. 'Desperately seeking Selznick: Cooptation and the dark side of public management in networks', Public Administration Review, 64 (2004), 681-93.

Parkinson, J. (2004) 'Why Deliberate? The Encounter between Deliberation and New Public Managers', Public Administration, 82 (4), 377-95.

Parkinson, John R, Deliberating in the real world: problems of legitimacy in democracy (Oxford, Oxford University Press, 2006). 
Parkinson John R and Jane Mansbridge eds., Deliberative systems: deliberative democracy at the large scale (Oxford: Oxford University Press, 2012).

Papadopoulos, Yannis, 'On the embeddedness of deliberative systems: why elitist innovations matter more' in, in John Parkinson and Jane Mansbridge eds., Deliberative systems: deliberative democracy at the large scale (Cambridge, UK, Cambridge University Press, 2012), 125-150.

Patashnik, Eric and Zelizer, Julian, 'The struggle to remake politics: Liberal reform and the limits of policy feedback in the contemporary American state', Perspectives on Politics, 11 (2013), 1071-1087.

Pateman, Carole 'Participatory democracy revisited', Perspectives on Politics, 10 (2012), 719.

Rose, Nikolas 'Community, Citizenship, and the Third Way', American Behavioural Scientist 43(2000), pp. 1395-1411.

Schram, Sanford F., and Basha Silverman. "The end of social work: Neoliberalizing social policy implementation." Critical Policy Studies 6.2 (2012): 128-145.Soss, Joe, Unwanted Claims: the Politics of Participation in the U.S. Welfare System. (Ann Arbor, MI: The University of Michigan Press, 2000).

Soss, Joe and Schram, Sanford, 'A public transformed? Welfare reform as policy feedback', American Political Science Review, 1010 (2007), 111-127.

Steiner, Jurg, Bachtiger, Andre, Sprondli, M, and Steenbergen, M, Deliberative politics in action: analyzing parliamentary discourse (Cambridge, Cambridge University Press 2005).

Stevenson, Hayley and Dryzek, John S, Democratizing Global Climate Governance (Cambridge: Cambridge University Press, 2014).

Stewart, Ellen A. "Seeking outsider perspectives in interpretive research: young adults and citizen participation in health policy." Critical Policy Studies 9.2 (2015): 198-215.

Stewart, Ellen. Publics and their health systems: rethinking participation. Springer, 2016.Teghtsoonian, Katherine. 'Depression and mental health in neoliberal times: A critical analysis of policy and discourse.' Social Science \& Medicine, 69 (2009): 28-35. 